lame, and experienced pain in walking. All the joints were practically normal except the left hip. The left hip showed sreat impairment of movement. There was only slight flexion, about 10 degrees, and very little loteral movement was possible. The $x$-ray examination showed very marked lipping possible. The $x$-ray examination showed very marked lipping, and bony changes round the left hip-joint. The patient had had all forms of medicinal treatment and had visited various spas withou any benefit. As it was obvious that medicinal treatment could not improve or affect the marked borry changes round the left and no other joint was affected, I advised surgical treatment.

operation.

On March 30th the operation of cheilotomy on the left hip was performed through a posterior incision in the capsule, securing free rotation and a considerable amount of abduction. The operation proved to be more difficult than in Case I, mainly on account of the bony deposit in the capsule at the margin of the acetabulum. The bony lip round the margin of the head of the femur was re moved for a considerable portion of its circumference, and the capsule was sewn up.

On the evening of the day of operation the patient was quite free from pain, and he is making an uneventful convalescence. There seems every prospect that the result in this case will be just as satisfactory as in Case I, for abduction and rotation already, only ten days after the operation, are free and painless, though there is more tendency to muscular spasm than in Case 1.

[Dr. W. H. O'Meara of Carlow writes on April 26th: I saw Major A. yesterday, and must congratulate you on the great success of your operative treatment. He can walk about with comfort, and can rotate, extend, and ubduct the leg freely.]

It is probable that the restoration of movement pro nuced by cheilotomy, while depending mainly upon the removal of actual bony obstacles to rotation and abduction is also due to another cause. The head of the femur is unduly large and the capsule is consequently stretched, and does not possess that reserve of "slack" which is necessary to allow a good range of movement. The restoration of this "slack" by the operation is an important factor which must not be lost sight of.

May we, in conclusion, utter a word of warning against the indiscriminate application of the operation in unselected cases. For cases where the constitutional or toxic element of osteo-arthritis predominates, the method is obviously unsuited, and other methods of treatment, including the vaccine treatment, of which one of us has made a special study, ${ }^{2}$ should always be tried. Nor should the operation be undertaken save under the ibest conditions, with ample assistance, with all possible aseptic precautions, and with the essential preliminary of a good stereoscopic radiograph of the joint.

The best and most suitable cases are probably those in which medical and vaccine treatment has improved the patient in relation to his or her general health and where the smaller joints (probably those most recently affected) have improved, but the one joint shows distinct osteitic clianges as described.

REFERENCES.

1 Transarticular Operations for Certain Difficult Fractures near the Knee and Elbow, by W. Sampson. Handley, BRITISH MeDical ocrinal, 19. Treston

\section{A CASE OF ENTEROLITHS}

$$
\text { [With Special Plate.] }
$$

$$
\text { BY }
$$

J. ANDERSON, M.B., Ch.B.ABERD.,

HONORARY ASSISTANT SURGEON, DUNDEE ROYAL INFIRMARY.

As $x$-ray photograph of enteroliths in situ must be comparatively rare. In fact, I can find no evidence of any such having been recorded. The main factors re sponsible for this appear to me to be: (a) Intestinal concretions are distinctly uncommon. ${ }^{1}$ (b) In many cases the symptoms are so insidious in their onset and of so long duration that medical aid is summoned only when there is evidence of intestinal obstruction, and the diagnosis is made when the abdomen-has been opened. (c) Only recently has $x$-ray examination become a routine method in abdominal diagnosis.

The case is that of J. O., a ploughman, aged 39, seen by me with Dr. Gowans of Broughty Ferry on July 23rd, 1912. Except for seven years, when he was working in an oilcake factory, he has followed this employment since the age of 13. His habits have been regular and he has had no other illness. - The history was that for the past eighteen years he had been subject to attacks of colic in the right iliac region, varying in duration from $a$ few minutes to half an hour, and recurring generally three or four times a month. They commenced with dis tension of the lower abdomen, associated with gradu. ally increasing discomfort till the pain suddenly began to diminish and the indisposition culminated in com. plete relief followed by the passage of a large quantity of flatus. He had also had flatulence not associated with pain. The bowels had been fairly regular, but he had had occasional attacks of diarrhoea followed by constipation. There had been no vomiting and no urinary symptoms. During the last month these attacks had increased in frequency and severity, and had been accompanied by marked anorexia and slight loss of weight.

On examination, the teeth were good and his tongue clean. An irregular tumour of stony hardness and about the size of the fist was felt in the right iliac fossa. It was fairly mobile, and gave the impression of being intimately connected with the caecum. I was unable to feel it by the rectum. He was advised to go to hospital for $x$-ray examination and probably exploratory operation but delayed till his general health began to suffer and his discomfort increased.

He was admitted to Dundee Royal Infirmary on August 20th, 1912. His condition on admission was very much as above noted but with a general aggravation of all symptoms and somewhat severe intestinal stasis; the tumour was less movable.

The $x$-ray plotograph reproduced was taken by Dr. Pirie and gave the foundation for definite diagnosis.

On Angust '22nd, under chloroform, I opened the abdomen through the right rectus (Battle's incision) The lower portion of the ileum was found to be very much increased in calibre, and its walls markedly bypertrophied The fumour consisted of two portions, the larger fixed at the ileo-caecal valve, the other free in the lumen of the ileum some 5 in. from its lower end.

The smaller concretion was removed with ease through an incision in the longitudinal axis of the gut. The por tion of bowel containing the second calculus could not be brought up to the ahdominal wound, so it was deemed expedient to pack off the general peritoneal cavity and attempt removal through the same intestinal.opening This enterolith was roughly hourglass-shaped, and im pacted at the valve, and the caecal portion had to be broken down and the mass delivered with a large stone forceps. The bowel was closed with Lembert sutures.

Convalescence was uneventful, and the patient rvas dis charged well on September 20th. He is now nearly 2 st. heavier than before the operation.

The specimens* look like pieces of compressed felt.

(a) The smaller, which was wedge shaped, with two large facets, measured $16 \times 14 \mathrm{~cm}$. in circumference.

(b) The larger showed no facet, and measured $19 \frac{1}{2} \times 24 \mathrm{~cm}$. (the last measurement is approximate, owing to damage in removal). The capsule and nucleus, which were well marked in the skiagram, were found chemically to consist mainly of calcium phosphate, while the intervening material appearcd to be mostly faecal and vegetable matter bound together by fine hair-like substance. Since removal they have lost quite half their weight.

The case is interesting mainly from the following points of view :

(a) The large size of the concretions.

(b) The fact that these, though situated at what is normally the narrowest portion of the gut, did not give rise to more marked obstructive symptoms.

(c) The duration of the symptoms without disturbance sufficiently grave to necessitate medical attention at an earlier date.

(d) The extreme value of $x$-ray examination in arriving at a correct diagnosis.

Two points of interest noted in the history were that porridge had been one of his most frequent articles of ditt,

* The specimens were shown at a meeting of the Forfarshire Medica? 
and that he very frequently bit hairs from his moustache and swallowed them

The patient was again referred to me in March, 1913, with a breaking-down tumour situated about the middle of Scarpa's triangle on his right leg. I excised it and found it to be a spindle-celled sarcoma growing from the superficial fascia.

His general condition is excellent.

REFERENCE.

1 BRItish MEDical JodRNAL, November 19th, 1912, p. 1282

\section{REMOVAL OF INTRATHECAL TUMOUR FROM LEMBAR REGION OF SPINAL CORD.}

BY

J. MICHELL CLARKE, and M.D., F.R.C.P.,

PHYSICIAN, BRISTOL GENERAL HOSPITAL.

\section{A. MORTON,} F.R.C.S., SURGEON, BRISTOL GENERAI HOSPITAL.
This case illustrates the symptoms produced when a tumour compresses both the upper roots of the cauda equina and the spinal cord itself, and affords another instance that these intrathecal growths are so often single anc? non-malignant.

\section{History.}

The patient was under the care of Dr. Harvey Bird, of Bridgwater, who recognized the nature of the case, and sent her to the Bristol General Hospital. She was married, aged 52, had had six children, and had enjoyed good health until the present illness; there was no suspicion of syphilis.

\section{Order of Symptoms.}

Towards the end of 1909 she began to suffer from "rheumatic pains" in the right thigh, which henceforth recurred at gradually decreasing intervals. In 1912 the pains became worse, they were sharp and shooting in character, from the hip down into the leg and foot, and the right leg became weak. In April, 1912, the pains greatly increased; she also felt " pins and needlcs" in the toes, and increasing numbness and loss of power in the whole limb. By May the right leg was paralyzed, and from this and increased pain she could no longer get about. At the end of May shooting pains were also felt in the left leg, though not so severe as in the right, and were accompanied by numbness and gradually increasing loss of power in it. She also suffered from pains in the back, and a feeling of tightness around the lower abdomen.

At the end of July, 1912, there was paraplegia; she was unable to walk or stand. For a fortnight during August she had retention of urine, but recovered control of her bladder under use of the catheter; from this time, however, she was liable to occasional incontinence. Bowels constipated. Severe pains continued until admission to Bristol General Hospital on September 7th.

Condition on ADMission.

She was well nourished, but had a drawn, haggard expression. She was completely paraplegic and moved or turned herself in bed with the greatest difficulty. Passive movements of the lower limbs caused great pain, especially at the joints. She complained so constantly of great pain, when moved or touched, that it was both difficult to examine her or to do anything for her ; possibly she was unnerved by the pain she had suffered, which had necessitated morphine injections. She slept badly. The thoracic and abdominal organs were normal. The urine was normal. The cranial nerves, upper extremities, and trunk muscles were entirely unaffected.

\section{Motor Symptoms.}

The right lower extremity could not be moved at all in any part of it; she could draw up the left thigh a little way and bend the left knee slightly, but these were the only movements possible in this limb.

The paralysis was of the flaccid type; there was double foot-drop and the toes were flexed.
The anterior thigh muscles were not wasted, except from disuse. There was marked wasting of all muscles below the knees in both legs, predominating in the tibialis anticus, peronei and extensors of feet, more marked on the right than on the left side, though the circumference of each calf measured the same. The glutei and hamstring muscles were also wasted.

\section{Electrical Reactions.}

Diminished reaction to both electrical currents was present in both quadriceps extensor muscles, especially the right, and in the glutei and hamstring muscles. Reaction of degeneration was present in tibialis anticus, peronei, extensors of toes, calf muscles, and plantar accessorius. 'The peroneal nerves reacted very feebly to the faradic current; to the constant the formula for the right nerve was $\mathrm{KCC}=0, \mathrm{ACC}=20$ milliampères, and for the left $\mathrm{KCC}=10$ milliampères, $\mathrm{ACC}=8$ milliampères.

Sensory Symptoms.

The sensory affection is shown on the chart (Fig. 1) Apparently the border of loss of sensation to cotton-wool
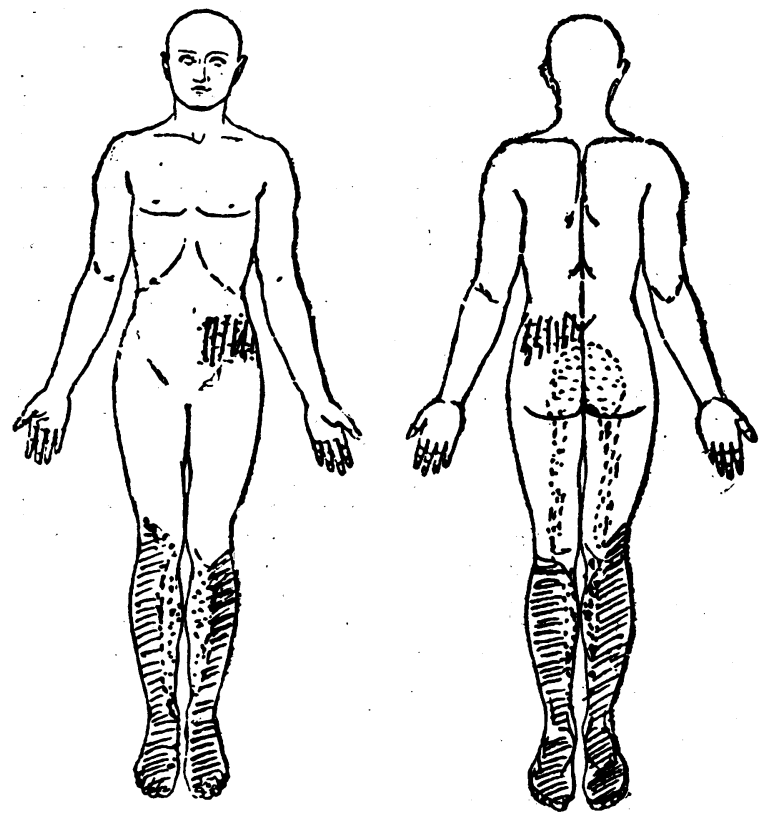

Fig. 1.- Loss of sensation to touch, pain, and temperature; dotted area, defective sensation to touch, pain, and temperature: IIII ill-defined band of hyperaesthesia.

and pin-prick was coterminous. The loss to heat and cold was absolute over the affected areas, whilst there was diminution of sensation to pressure over the same distri. bution. Both feet felt very cold to the touch. There was also some loss of the sense of position of the limbs; she had constantly a feeling that her legs were floating in the air and not lying on the bed. There was an indefinite zone of hyperaesthesia on the left side in the lower lumbar or upper sacral and lower abdominal regions.

The chart gives the result of a number of observations on the sensory changes, and can be regarded as approximately correct; she was a difficult patient on whom to make any investigations of this kind.

\section{Reflexes.}

Abdominal present and normal. Plantar absent or (?) feebly flexor on strong stimulation.

Knee-jerks and ankle-jerks present. Right knee-jerk active. Marked ankle clonus on right side, not on left; no knee clonus. The bladder was not distended; there was occasional slight incontinence of urine, which seemed partly due to inadvertence, as she was not always aware of it; she could not hold her water for more than an hour at a time. There was no anaesthesia of bladder or rectum. The anal sphincter contracted normally.

There were no trophic lesions of the limbs, and no actial bedsores; but on admission the skin over the sacral and lower lumbar regions of the back was in a very unhealthy state and on the verge of breaking down. 
DR: J. ANDERSON : A CASE OF ENTEROLITHS.

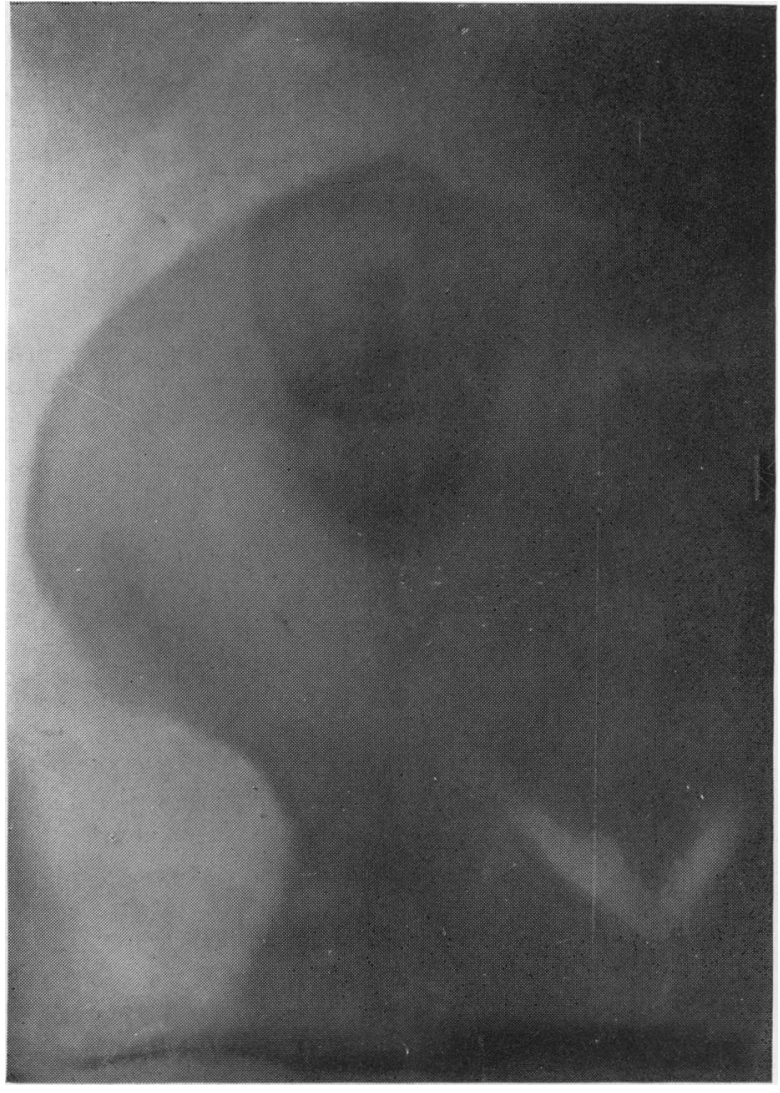

FIG. 1.-Skiagram.

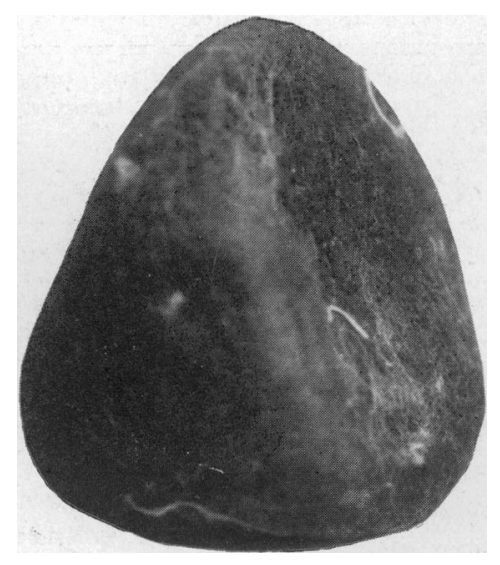

FIci. 3.-Enterolith No. 1
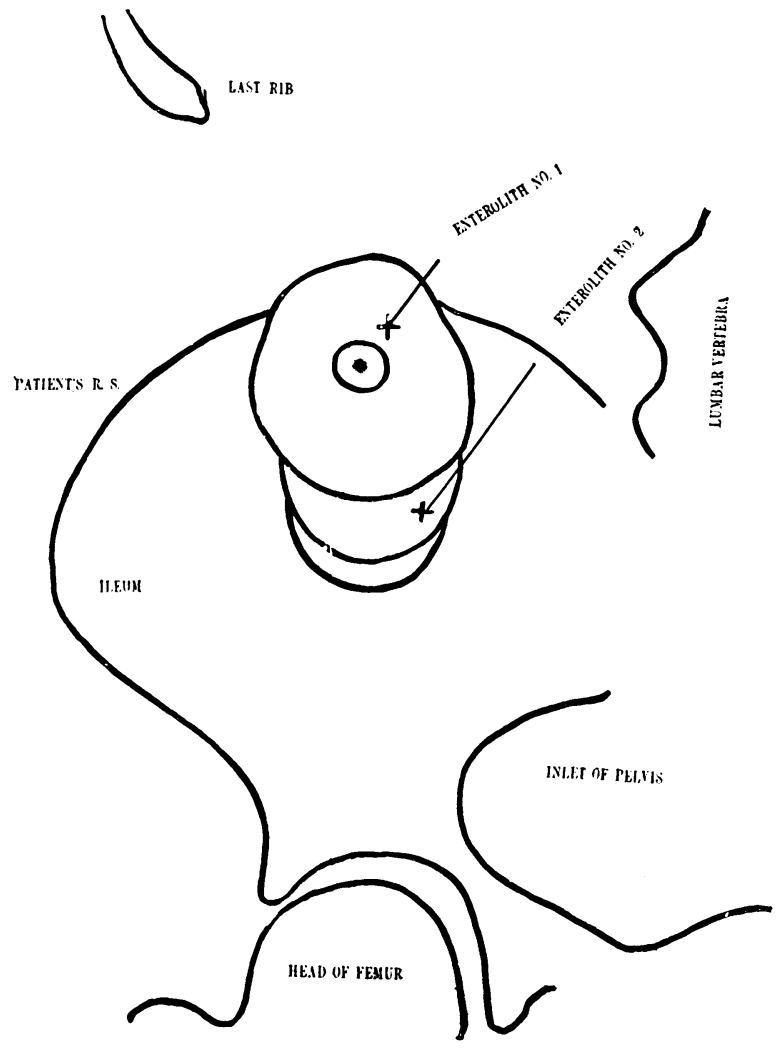

FIt. 2.-Diagram of Fig. 1.

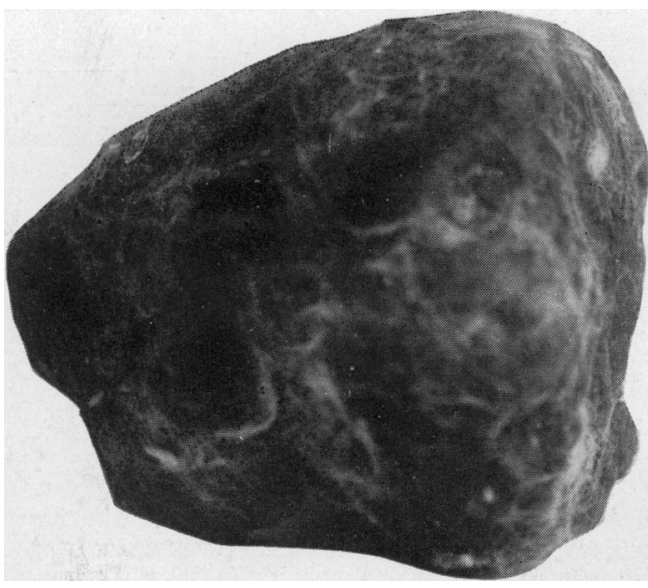

Fig. 4-Part of enterolith No. 2. The portion in the cuecum had to be crushed to facilitate removal. 